\title{
CORRIGENDUM
}

\section{Electron acoustic super solitary waves in a magnetized plasma. J. Plasma Phys. 84 (4) (2018) - CORRIGENDUM}

\author{
T. Kamalam, S. V. Steffy and S. S. Ghosh \\ doi:10.1017/S0022377818000740, Published by Cambridge University Press, \\ 27 July, 2018
}

We have noticed that the table 1 had some errors on its last three columns. Now the corrected values are given in the table.

$\begin{array}{ccccc}k \lambda_{\text {iff }} & \omega / \omega_{\text {pe }} & V_{\text {phase }}\left(\mathrm{m} \mathrm{s}^{-1}\right) & V_{\text {tic }}\left(\mathrm{m} \mathrm{s}^{-1}\right) & V_{\text {tih }}\left(\mathrm{m} \mathrm{s}^{-1}\right) \\ & 0.0368 & 6.6712 \times 10^{5} & & \\ 0.07 & 0.0054 & 9.7892 \times 10^{4} & 1.1987 \times 10^{5} & 1.8954 \times 10^{5} \\ & 0.0044 & 7.9764 \times 10^{4} & & \\ & 0.2837 & 7.2002 \times 10^{5} & & \\ 0.5 & 0.026 & 6.5987 \times 10^{4} & 1.1987 \times 10^{5} & 1.8954 \times 10^{5} \\ & 0.0075 & 1.9035 \times 10^{4} & & \\ & 0.4949 & 6.3436 \times 10^{5} & & \\ 0.99 & 0.0558 & 7.1524 \times 10^{4} & 1.1987 \times 10^{5} & 1.8954 \times 10^{5} \\ & 0.0075 & 9.6134 \times 10^{3} & & \end{array}$

TABLE 1. Comparison between the thermal and phase velocity for the chosen parameters.

The first line of p. 7 is corrected as 'we have assumed that the plasma contains both $\mathrm{H}^{+}$and $\mathrm{O}^{+}$, the former being the cooler component with $\mu_{i}=0.4$ '.

† Email address for correspondence: kamalam.unom@gmail.com 